\title{
Comparing Variability of Parameters between Roller Bed Brakes Testers and Dynamometric Platform of Ministry Of Transport Facilities
}

\author{
Senabre, $C^{1}$, Valero, $S^{2}$ and Velasco, $E^{3}$ \\ ${ }^{123}$ Departamento Ingeniería Mecánica y Energía, Área: Mecánica. \\ Edificio Innova. Avda de la Universidad sn. \\ Universidad Miguel Hernández \\ 03202 Elche, Spain.
}

\begin{abstract}
This study gives a comparison between which parameters may vary when braking on two different Ministry of Transport (MOT) brake testers, such as roller bed brake tester and dynamometric platform. A comparative study between both types of brake testers have been carried out by the mechanical engineering staffs at the mechanical laboratory at the Miguel Hernández University in Elche to determinate which parameters can vary the result of the test.
\end{abstract}

\section{Introduction}

This is work deals the study of the influence of variables in two different Ministry of Transport brake testers such as roller bed brake tester and dynamometric platform brake tester, in the longitudinal braking action and sliding.

The aim of the study is to find out a vehicle's braking capacity by measuring slippage on two brake testers at MOT centres, compare the measurements with each other when varying some parameters, and then use the results to assess the reliability of the machine in testing brake systems.

When a vehicle is taken to an MOT testing facility, this includes a brake test made on a roller bed to check the brake circuit. This research analyses how far the tyre parameters studied affect the measurements taken on the roller bed. Ultimately, we study if the MOT brake tester correctly assesses the condition of brakes $100 \%$ efficiently in comparison with measurements taken from the dynamometric platform brake tester.

\section{Mathematical demonstration}

To know which parameters influence on the brake measurement on brake testers, we have to analyzemathematicallythe brake equations.

Considering:

$r_{e}=$ Effective radius of the wheel on rollers

$r_{e p}=$ Effective radius of the wheel on flat ground

$\mathrm{r}_{2}=\mathrm{r}_{3}$ radius of rollers

$\mathrm{M}=$ Sum of moments

$\mathrm{Mf}=$ Braking torque applied to the vehicle wheel

$\mathrm{Mt}=$ Roller tractor torque, $\mathrm{Mt} 2=\mathrm{Mt} 3$

$\mathrm{F} 2=\mathrm{F} 3=$ Roller tractor force,

$\mathrm{Fr}=$ Frictional force, $\mathrm{Fr}_{2}=\mathrm{Fr}_{3}$

$\mu=$ Rollers roughness

$\mathrm{P}=$ Weight on the wheel

$\mathrm{Re}=$ Effective radius of the wheel

$\operatorname{Cos} \theta=$ Angle between the symmetry axis and the line between wheel-roller centers.

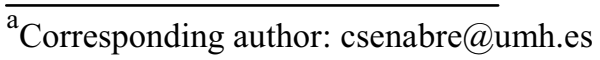




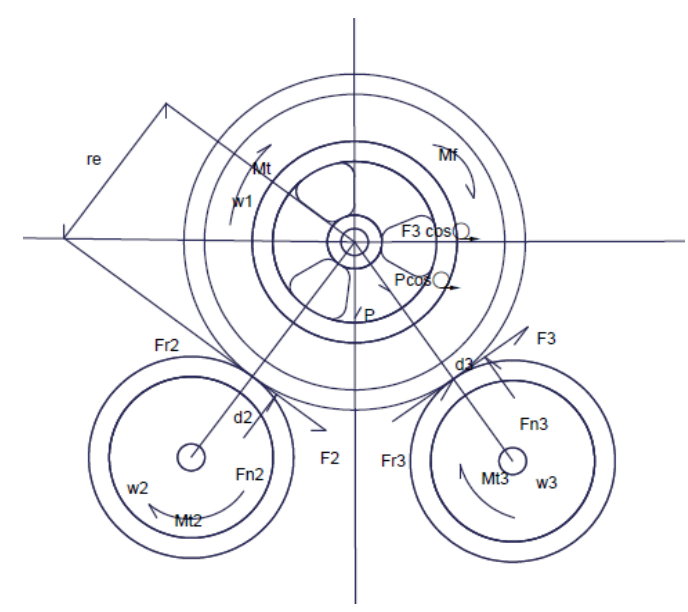

Figure 1. Parameters in the brake test on rollers.

On roller bank there is not advance so: $\mathrm{I} . \alpha=0$

Forces and moments acting on the wheel when braking on dynanometic platform:

Forces in the $\mathrm{x}$ axis [5-7]:

$$
\sum F_{x}=m a
$$

Ff

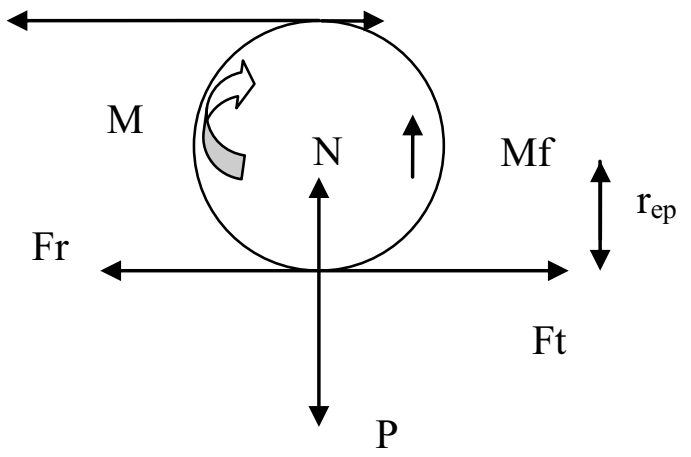

Figure 2. Movement of the wheel on dynamometric plate

$$
->\mathrm{ma}=\text { Fx - Fr- Ff }
$$

Forces on the y axis:

$$
\sum F y=0,0=\mathrm{P}-\mathrm{N}, \mathrm{N}=\mathrm{P}
$$

In Table 1 formulas of the braking torque on dynanometric platform and on roller bed can be

\begin{tabular}{|c|c|}
\hline On roller bank & On dynanometric platform \\
\hline $\begin{array}{l}\mathrm{Mf}=2 \mathrm{Mt}-2 \frac{\left.\mu \cdot P \cdot r_{(5)}\right)}{\cos \vartheta} \\
\mathrm{Mf}=2 \mathrm{r}_{\mathrm{e}} F_{3}-\mathrm{I} \cdot \alpha-2 F r_{3} \cdot r_{e}(6) \\
\mathrm{Mf}=2 \mathrm{r}_{\mathrm{e}} F_{3}-\mathrm{I} . \alpha-\frac{2 \mathrm{r}_{\mathrm{e}} \cdot \mu \cdot P}{\cos \vartheta}(7)\end{array}$ & $\begin{array}{l}M f p=-I \alpha+F x \cdot r_{e p}-\text { Fr } \cdot r_{e p} \\
M f p=-I \alpha+F x \cdot r_{e p}-\mu . P \cdot r_{e p}(10)\end{array}$ \\
\hline $\mathrm{F}_{3}=\frac{\mathrm{I} \cdot \alpha}{2}+\frac{\mathrm{Mf}}{2 \mathrm{r}_{\mathrm{e}}}+\frac{2 \cdot \mu \cdot P}{\cos \vartheta}(8)$ & $\mathrm{F}_{\mathrm{x}}=\frac{I \alpha+M f+F r \cdot r_{e}}{r_{e}}(11)$ \\
\hline
\end{tabular}
compared:

Table 1. Formulas on both cases

same conditions. Comparing brake torke on dynanometric platform and on roller bed tester formulas we will see the differences:

If ; $\mathrm{Mfr}=\mathrm{Mfp},($ subindex $\mathrm{r}=$ rollers, $\mathrm{p}=$ platform) at constant velocity we have:

$$
\begin{aligned}
2 . \mathrm{r}_{\mathrm{e}_{r}} F_{3}-F r . r_{e r}= & \text { Fx } . \mathrm{r}_{\mathrm{ep}}-\mathrm{Fr} . \mathrm{r}_{\mathrm{ep}->} \mathrm{r}_{\mathrm{e}_{r}}\left(2 \mathrm{~F}_{3^{-}}\right. \\
& \left.\mathrm{Fr}_{3}\right)=\mathrm{r}_{\mathrm{ep}}\left(\mathrm{Fx}_{\mathrm{p}}-\mathrm{Fr}_{\mathrm{p}}\right)
\end{aligned}
$$

Or what it is the same;
As we can see, the drag force on the roller is not the same as on level ground, assuming a zero slip, so the braking torque in either case will depend primarily on factors such as:

- The effective radius on flat ground

- The effective radius on rollers.

- Tyre presure

- Acceleration during the Test

- The separation of the rollers and the $\cos \vartheta$

- The weight on wheel

- The adhesion of the wheels on the ground or rollers and the rolling resistance. 


\section{Testing methods}

The vehicle used in the research was a used Renault 21 "Nevada" 7-seater, diesel with a mileage of 90,000 kilometres. It is equipped with front disc brakes with sliding clamps and uses DOT 4 brake fluid with a tandem brake pump. The rear wheels have drum brakes.

The test on the brake roller tester at the MOT centre is carried out by placing the vehicle on rollers. The emergency brake should not be actuated. The car stops on the roller bed [1]. Then the rollers rotate at $5 \mathrm{~km} / \mathrm{h}$ of speed. This velocity is indicated in the "MOT procedure manual" [2] from Ministry of Industry, Tourism and trade of Spain (2014) [3-4]. Brake pedal will be pressed until $100 \%$ of slippage is obtained.

The torque on the rotation axis of the rollers is measured using a strain gauge. The pressure in the brake hydraulic circuit on the right wheel of the vehicle is also measured using a hydraulic sensor in the hydraulic pipe of the right wheel.

To calculate ant slippage, the angular velocity of the rollers and vehicle wheels are measured using two OMRON encoders: the first is fitted to the brake roller tester and the second is in contact with the front, righthand wheel of the vehicle.

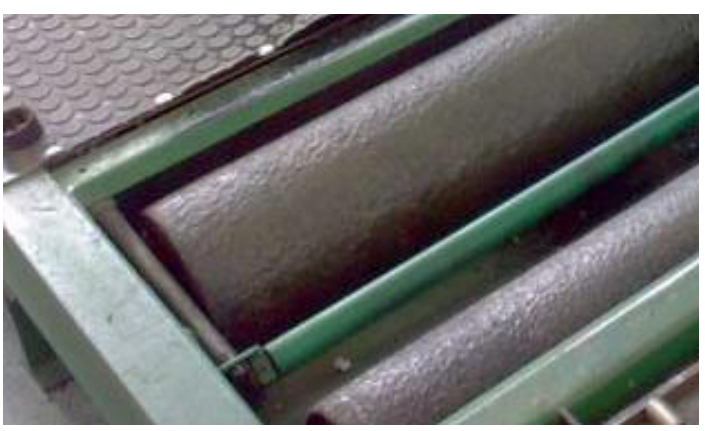

Figure 3.MOT-390, $\mu=33(\mu \mathrm{m})$

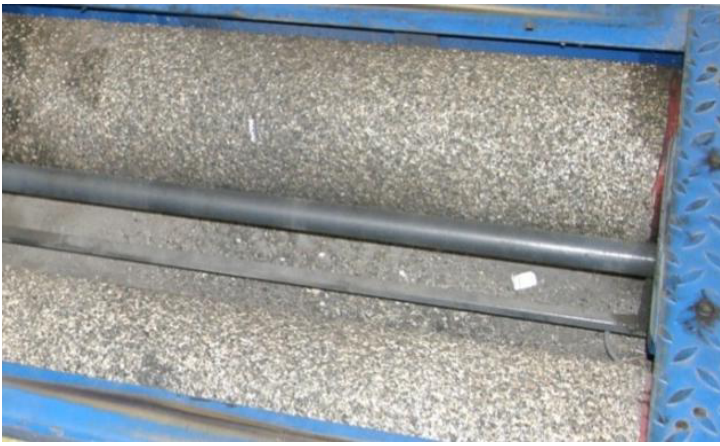

Figure 5.MOT-410, $\mu=49(\mu \mathrm{m})$

Mot brake testers analyzed were:

MOT Station 450 from our laboratory at the campus Miguel Hernandez University from Elche, with a distance between rollers of $450 \mathrm{~mm}$.

MOT Station 410 , the city of Elche. The distance between rollers is $410 \mathrm{~mm}$.

MOT Station 390, located at the Torreblanca building, at Miguel Hernández University from Elche. The distance between rollers is $390 \mathrm{~mm}$.
Data were recorded using an LMS Pimento portable, multi-channel analyser.

To ensure that the rotation of the encoders was synchronised with the rollers and the wheel, a spring was placed ensuring good contact.

The slippage using the following expression: Slippage $=1-$ speed of vehicle speed of fifth wheel

Each of these measurements was obtained by taking the average of ten braking data sets with the same conditions; dispersion of each group of brake measurements was less than $3 \%$.

\section{Experimentation}

The measurements obtained from tests were: the brake pressure on the vehicle and the slippage on the braking wheel.

As can be seen in the pictures below, the roughness of rollers at MOT-450 and MOT-410 were the same, 49 microns, while at the MOT-390 they were lower, 33 microns, because the equipment had been used thousands of times for brake tests in the active period at MOT facilities in Alicante.

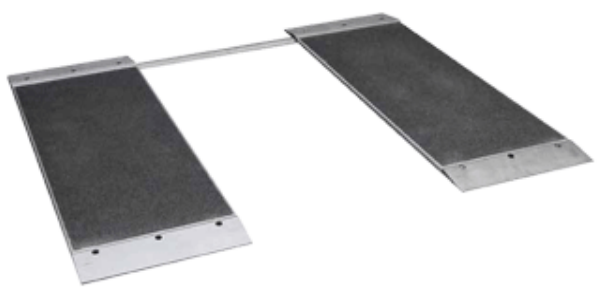

Figure 4.MOT platform (1.5 m x $2.02 \mathrm{~m}, 0.6 \mathrm{~m}$ each)

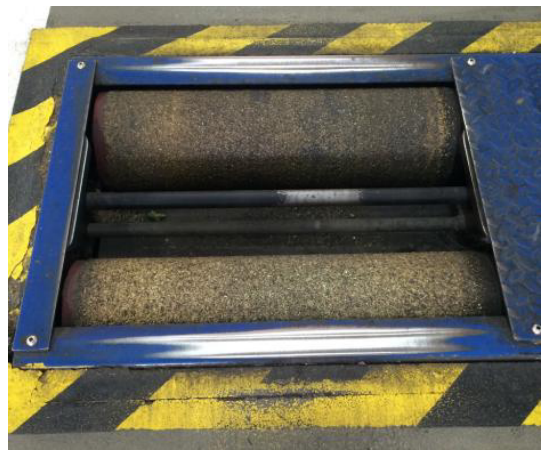

Figure 6.MOT-450, $\mu=49(\mu \mathrm{m})$

Dynamometric platform from our laboratory at the campus Miguel Hernandez University from Elche

Tests on the four MOTs brake testers were performed with the same Continental Contact tyre, to know that the differences obtained in the measures were not due to this parameter. Tyres were inflated from between 1 and 3 bar (1, 1.5, 2, 2.5 and 3). A comparative analysis was made of the braking and slippage measurements for the same test conditions carried out with different tyre pressures. 


\section{Variability of experimental data obtained on roller bed brake tester}

With the same roller diameter and different distance between rollers, (the numerical value after the MOT acronym indicates the roller base in $\mathrm{mm}$ ), to analyze the influence of this parameter in brake data obtained.

Differences in measurements were obtained due to the decrease of $40 \mathrm{~mm}$ of distance between rollers (MOT-450 and MOT-410). The roughness of rollers was the same: $49 \mu \mathrm{m}$.

It was observed that the car will pass the test only with tyre pressure higher than 1.5 bar or more at MOT410 , when the brake system is right. However, with the same car and the same tyre it will never pass the test at MOT-390 while it will always pass the test at the MOT450 tester with any tyre pressure. It has been proven that a vehicle will have the highest possibility of passing the test using the MOT-450 secondly MOT-410, and finally the MOT-390.

The influence of the roughness on the brake data measured have been analyzed by comparing the measurements between MOT-390 and MOT-410. 32\%. Lower brake data values was obtained using the MOT390 using the same Continental Contact tyre. This difference was due to the different distance between rollers and tyre and due to the different roughness of roller surface, $49 \mu \mathrm{m}$ for MOT 410 and $33 \mu \mathrm{m}$ at MOT390 . The roughness values were measured with a digital profilometer.

\begin{tabular}{|c|c|}
\hline Parameters & From 1 to 3 bar \\
\hline \multirow[t]{2}{*}{ Tyre pressure } & At MOT-450 maximum di \\
\hline & MOT-390 max. \\
\hline Rollers roughness & It decreases $27,7 \%$ when \\
\hline MOT wheel base & $+11,6 \%$ (1bar) to $-1,5 \%$ \\
\hline Weight increment & $+2,5$ to $+12 \%$ increasing + \\
\hline \multicolumn{2}{|c|}{$\begin{array}{l}\text { Thus, it has been demonstrated that the measure of } \\
\text { ke obtained from roller MOT testers depends on the } \\
\text { p pressure, the distance between rollers, the roughness } \\
\text { collers and the weight on the wheel. The same vehicle, } \\
\text { h the brake system in perfect condition, can pass or } \\
\text { the brake test, depending on which of the MOT } \\
\text { ters were used. } \\
\text { Finally, it can be concluded that these parameters } \\
\text { ect the brake measurements at MOT test centers and } \\
\text { tort the results of the brake test. }\end{array}$} \\
\hline $\begin{array}{l}\text { Variability of } \\
\text { namometric } p\end{array}$ & obtained on a \\
\hline
\end{tabular}

Through various tests it has been possible to identify the importance of tyre deformation at the contact patch. It is
We analyzed the influence of increasing the weight on the car by $108 \mathrm{~kg}$ on the front axle with $54 \mathrm{~kg}$ on each wheel. Brake data was measured with different tyre pressures with the same Continental Contact tyre.

This addition of weight to each wheel on the front axle affects the brake measurements at MOT-450 by between $2.5 \%$ with 1 bar tyre pressure and $12 \%$ with 2.5 bar tyre pressure. So the more the weight increases so too does the possibility of passing the test, even more so when the tyre pressure increases.

This phenomenon is produced due to the weight on the front axle produces a bigger contact area for friction between the tyre and the roller, therefore that the maximum slip appears later, then more brake torque has to be applied to the wheel to obtain $100 \%$ of slippage on the MOT brake tester.

Therefore, the maximum brake value when the maximum slip point is obtained will be higher as the weight increases because the effective radius re will be lower because of the weight on the wheel. [8], If $\cos \theta$ is higher brake torque, Mf, to stop the wheel on the rollers will be higher.

Moreover, when the radius decreases because the weight increases, the brake torque to stop the vehicle increases.

To summarise see Table 2, \% of variation when parameters studied changed.

\section{tyre pressure}


Finally, it is important to emphasize the limited influence of speed in the transmission of forces on the tyre-road contact in the range between 0 and $8.4 \mathrm{~m} / \mathrm{s}(0$ to $30 \mathrm{~km} / \mathrm{h}$ ), no as for higher speeds, and the importance of conducting a pre-entry plate and adhesion control for variations in the rolling contact surface [8-9].

\section{Comparision between both measurements}

To understand the discrepancy of measurements between roller bed brake tester and dynanometric platform, (with the same tyre and the same wheel inflation pressure and the same load on wheel), it should be analyzed the variation of the tyre contact patch.

The tyre contact patch will influence: adhesion, rolling ised effort, and rolling resistance.

For this study it was used a Tyre type: Radial 155/70R13 , wheel pressure: 2,3 bar, vehicle used: Ford fiesta.

Data results of tyre contact patch on rollers and on a dynanometric platform is shown below in table 3 .

Table 3: Área of tyre contact patch on rollers and on a dynanometric platform

\begin{tabular}{|l|l|}
\hline & Contact area $\left(\mathrm{mm}^{2}\right)$ \\
\hline Roller bed & $\begin{array}{l}\text { Area2 }=24.59 \mathrm{~mm}^{2} \\
\text { Perimeter }=23.31 \mathrm{~mm} \\
\text { Area } 3=23.45 \mathrm{~mm}^{2} \\
\text { Perimeter }=21.46 \mathrm{~mm}\end{array}$ \\
& Total:48,04 $\mathrm{mm}^{2}$ \\
& $\begin{array}{l}\text { Radio of laded wheel: } \\
\text { r=26,6 mm }\end{array}$ \\
\hline $\begin{array}{l}\text { Dynanometric } \\
\text { platform }\end{array}$ & $\begin{array}{l}\text { Area } 1 \\
\text { Perímeter }=63.83 \mathrm{~mm}\end{array}$ \\
& $\begin{array}{l}\text { Radio of laded wheel: } \\
\text { R=26,3 mm }\end{array}$ \\
& \\
& \\
\hline
\end{tabular}

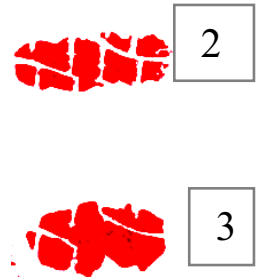

Figure7.

Tyre tread on rollers

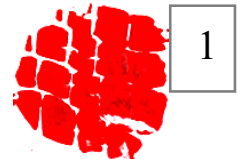

Figure 9.

Tyre tread on

dynamometric plate

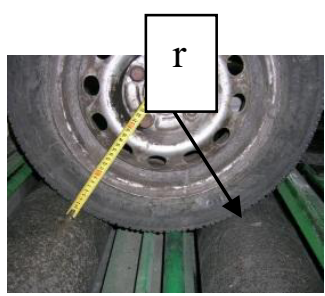

Figure 8.Tyre on rollers

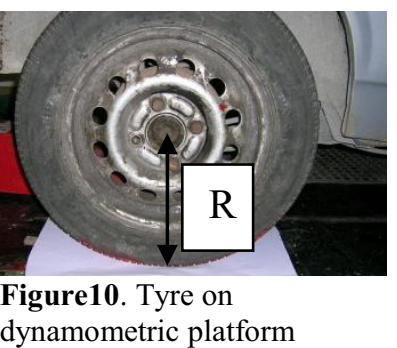

\section{Discussion and Conclusions}

When a vehicle is tested in the MOT facilities an objective brake test would be expected. Therefore, measurements should not be influenced by any other parameter. We only need to know if the brakes are in good condition or not.

The brakingstateis checked by measuring brake effectiveness. Efficacy must overcome are jection threshold of $50 \%$, which is the same for all Spanish MOT brake testers independent of the characteristics of the individual MOT brake test used.

We have obtained many experimental data. Each time a parameter influence was studied.

According to data obtained, the braking required to stop the wheel increases as tyre pressure increases at whichever MOT brake tester is used, when the same Continental Contact tyre is used.

With a higher tyre pressure, the tyre deforms less so the contact area between the wheel and the roller is lower. With a smaller contact area between the tyre and the rollers a higher torque will be required to stop the wheel on the roller tester and also on a dynamometric platform.

Variation of distance between rollers from $450 \mathrm{~mm}$ to $410 \mathrm{~mm}$ produces a variation in the measurements gathered by the MOT brake sensor, from $1.4 \%$ for 3 bar tyre pressure to $11.6 \%$ for 1 bar tyre pressure.
On the other hand it has been demonstrated that variations of angles of the wheel will increase the slippage on rollers and on the dynamometric platform so brake measurements will vary when angles (such as: camber angle, caster angle, alignment toe) vary.

Therefore, it has been demonstrated that depending on other extrinsic factors to the brake system, the vehicle would pass or not the rejection threshold. Moreover it could not pass the test with brakes in good conditions.

Thereby, we can cast doubt on the suitability of a brake roller tester and dynamometric platform to determine whether the brake system is in good condition or not.

\section{Acknowledgements}

I would like to thank for the grant: "Ayudas para la realización de Proyectos I+D para grupos de investigación emergentes" GV/2015/034

\section{References}

1. Standardization of criteria for evaluation of defects diagnosed during the inspection of vehicles, CITA (2014). 
2. European Community. Directive 2002/78/EC Official Journal of the European Communities, L 267/23, October 4, (2002).

3. MOT Inspection Procedures Manual station, Ministry of Industry, Tourism and Trade of Spain (2014).

4. NationalRegulation Vehicle Inspection in Law No. 29237, Ministry of Industry, Tourism and Trade of Spain (2014).

5. Pablo Luque, Daniel Álbarez, Carlos Vera. Automobile Engineering, Systems and Dynamic Performance. Publisher: Thomson.

6. F. Aparicio y C. Vera, Theory of vehicles, vol.2, 2001.

7. J. C. Dixon, Tyres, Suspension and Handling, Society of Automotive Engineers, Inc. The Open University, Great Britain, 1996.

8. Modelo de contacto neumático-calzada a baja Velocidad. Daniel García-Pozuelo Ramos

9. Abella, M. M. Modelo de comportamiento de placa alineadora. PhDthesis, Departamento de Ingeniería Mecánica. Universidad Carlos III deMadrid. (2001). 